\title{
SOSIALISASI TANGGAP BENCANA MELALUI APE (ALAT PERAGA EDUKATIF) DI SDN KEBOIRENG, KECAMATAN BESUKI, KABUPATEN TULUNGAGUNG
}

\author{
Ahmad Fahrudin \\ Fakultas Tarbiyah dan Ilmu Keguruan IAIN Tulungagung, Email: fahru.cendana@ gmail.com
}

\begin{abstract}
Abstrak
Desa Keboireng, Kecamatan Besuki, Kabupaten Tulungagung adalah wilayah yang terletak dekat dengan pantai Samudra Hindia. Dengan dibangunnya Jalur Lintas Selatan (JLS) yang melewati Desa Keboireng menjadikan Pantai Gemah sebagai tempat wisata yang ramai, penduduknya pun banyak yang mencari penghasilan di sepanjang JLS dan pantai itu sendiri. Sebagian yang lain penduduknya berprosi sebagai petani. Akan tetapi banjir sering terjadi di desa ini, selain itu ada gempa dan longsor yang terjadi di sepanjang JLS. Panen menjadi gagal dan longsor yang terjadi memakan korban jiwa. Warga yang mencari nafkah di JLS dan pantai menjadi hal baru, sehingga upaya cara tanggap terhadap bencana yang setiap waktu mengintai perlu diberikan kepada warga masyarakat. Tujuan pengabdian ini adalah untuk memberi kesadaran dan tanggap terhadap bencana yang datangnya tidak bisa diprediksi. Metode yang digunakan adalah observasi, kemudian mengadakan sosialisasi dengan ceramah, simulasi, dan tanya jawab dengan peserta adalah seluruh siswa-siswi SDN Keboireng, Kecamatan Besuki, Kabupaten Tulungagung. Hasil dari pengabdian dan penelitian ini adalah siswa-siswi antusias, tertarik, dan senang terhadap sosialisasi yang telah dilakukan. Sehingga siswa-siswi dengan ketertarikan tersebut mampu mengaplikasikan materi yang diajarkan ketika saatnya bencana datang. Selain itu disampaikan kepada siswa-siswi untuk terus menjaga lingkungan dan alam agar bencana bisa dicegah.
\end{abstract}

Kata Kunci: sosialisasi, tanggap, bencana, APE.

\begin{abstract}
Keboireng Village, Besuki district, Tulungagung Regency is an area located close to the Indian Ocean coast. With the construction of the Southern Cross Route (JLS) that passes through Keboireng Village, making Gemah Beach a busy tourist spot, many residents also look for income along with the JLS and the beach itself. Some of the other resident's work as farmers. However, floods often occur in this village. Besides that, some earthquakes and landslides occur along with JLS. The harvest failed and the landslides that occurred took lives. Residents who make a living in JLS and beaches are new so that efforts to respond to disasters that lurk at any time need to be given to the community. The purpose of this service is to provide awareness and response to unpredictable disasters. The method was an observation, then held socialization with lectures, simulations, and questions and answers with all the students of SDN Keboireng, Besuki District, Tulungagung Regency. This dedication and research results show that students are enthusiastic, interested, and happy with the socialization that has been done. So that students with this interest can to apply the material taught when the time for disaster comes. Also, it was conveyed to students to continue to protect the environment and nature so that disasters can be prevented.
\end{abstract}

Keywords: socialization, response, disaster, APE 


\section{PENDAHULUAN}

Desa Keboireng, Kecamatan Besuki, Kabupaten Tulungagung terletak di dekat pantai dan berbatasan dengan Samudra Hindia (Anon n.d.). Jarak antara desa dengan pantai tidak terlalu jauh. Perkiraan hanya $2 \mathrm{~km}$ saja. Dan hanya dipisahkan dengan dataran tinggi yang ketinggian tidak terlalu tinggi.

Sebagian besar penduduk dari desa ini adalah sebagai petani, karena memang meski berada di dekat pantai, namun persawahan di desa ini masih sangat luas. Maka inilah yang menjadi lapangan untuk mendapatkan penghasilan sebagai sarana mencukupi kebutuhannya sehari-hari. Meski lokasi Desa Keboireng tidak berada pada pesisir pantai, ancaman musibah berupa banjir, tanah longsor, ataupun meluapnya air dari lautan bisa saja terjadi. Sebab bencana apapun dapat melanda apa saja, di mana saja, dan kapan saja (Anisah 2019).

Tentu ini menjadi sesuatu yang penting untuk menjadi landasan dalam pemberian edukasi di masyarakat, agar ketika terjadi bencana masyarakat sudah mengetahui bagaimana seharusnya menghadapi sebuah bencana yang datang, sehingga kemungkinan terburuk mampu diminimalisir (Afrian 2020). Mencegah lebih baik daripada menanggulangi.

Bencana yang sering terjadi di Desa Keboireng memang bukan tanah longsor atau tsunami. Yang sering terjadi adalah banjir. Sering terjadi banjir ini dikarenakan aliran air dari pegunungan sebelah selatan yang pohon-pohon penyangga air memang sangat minim. Pepohonan merupakan salah satu aspek penting utuk kestabilan lingkungan khususnya mengendalikan air (Binsasi et al. 2017). Hal ini yang menyebabkan air dari banjir ini menggenangi seluruh persawahan di Desa Keboireng ini, sehingga ketika akan menjelang panen, maka petani nyaris gagal keseluruhan, tentu ini menjadi musibah bagi warga. Bahkan warga Desa Keboireng pernah urunan secara swadaya untuk membangun tanggul dalam mencegah banjir yang memang udah menjadi langganan di desa ini (Baso n.d.).

Kegiatan Sosialisasi Tanggap Bencana ini dilaksanakan di SDN Keboireng, Kecamatan Besuki, Kabupaten Tulungagung. Target pengabdi adalah anak-anak selain pertimbangan kesadaran siaga bencana sejak dini, anak-anak rentan terhadap bahaya tenggelam sehingga menjadi prioritas dalam penanganan bencana banjir. Pemberian edukasi ini melalui banyak pertimbangan ketika diberikan kepada anak-anak, sebab edukasi kepada anak sedini mungkin terhadap sadar bencana penting dilakukan. Jika edukasi ini sudah dilakukan sejak dini, maka sadar bencana seiring perkembangan anak ke arah yang lebih dewasa akan terus terawat dan berkembang (Pahleviannur 2019).

Berdasarkan hasil observasi pada tanggal $29-31$ Januari 2020 di setiap ketua RT dengan jumlah sebanyak 15 orang pada Desa Keboireng, diperoleh informasi mengenai pengetahuan masyarakat khususnya tingkat Sekolah Dasar tentang kebencanaan masih sangat minim. Hal ini disebabkan karena saat ada penyampaian materi kebencanaan dan simulasinya dari BPBD (Badan Penanggulangan Bencana Daerah) tidak semua elemen masyarakat mendapatkannya, yakni hanya pada daerah pesisir pantai saja. Padahal Desa Keboireng merupakan wilayah yang memungkinkan untuk mendapatkan ancaman bencana kapan saja. Tentu saja hal tersebut sangat disayangkan, karena mereka memiliki hak untuk mengetahui hal-hal yang harus dilakukan sebelum, saat terjadi, dan setelah terjadi bencana. Idealnya semua harus mendapatkan pemahaman dan pengetahuan tentang sadar bencana ini (Hayudityas 2020).

Bersumber dari penuturan informasi-informasi tersebut akhirnya diambillah inisiatif untuk mengadakan sosialisasi kebencanaan kepada seluruh siswa-siswi. Tujuan adalah supaya siswa-siswi paham akan hal-hal kebencanaan, langkah yang harus dilakukan, dan kemungkinan-kemungkinan bencana yang akan terjadi di desa Keboireng. Bagaimanapun bencana merupakan salah satu faktor yang akan menghambat pertumbuhan dan perkembangan roda pendidikan, perekonomian dan lain sebagainya (Oktaviani 2020). Dengan dibekalinya materi kebencanaan dari BPBD yang sebelumnya peneliti dapatkan dalam acara pembekalan, selanjutnya disampaikan kepada siswa-siswi untuk dijadikan pondasi dasar dalam penanggulangan bencana. Pembekalan sejak dini akan sangat menguatkan pengetahuan dan keyakinan siswa-siswi terhadap arti pentingnya sadar bencana, khususnya yang berada di Desa Keboireng.

Edukasi lingkungan hidup sejak dini ini dilakukan agar selain menanggulangi dan persiapan ketika 
bencana datang, Siswa-siswi juga diberikan pengetahuan betapa pentingnya memelihara dan merawat lingkungan yang ada di sekitaran Desa Keboireng (Kurniawan et al. 2019). Ini merupakan salah satu langkah kecil untuk mencegah terjadinya bencana, dengan sikap bijak terhadap lingkungan, tidak merusak, dan tidak membuat pencemaran apapun di lingkungan sekitar, sudah merupakan langkah meminimalisir terjadinya bencana (Khairul Rahmat and Kurniadi 2020).

Sosialisasi yang dilaksanakan ini menggunakan APE (Alat Peraga Edukatif), APE ini menjadi sesuatu yang vital di dalam kegiatan ini sebab mampu menarik minat siswa-siswi belajar tanggap bencana ini dengan sangat menyenangkan, dengan APE siswasiswi mampu belajar sambil bermain, ini sesuai dengan kondisi psikologis anak-anak, karena masa anak-anak adalah bermain. Selain itu dengan APE kualitas sosialisasi akan mampu menghasilkan sesuatu yang maksimal (Oktradiksa and Aufa 2019).

Studi atau penelitian terdahulu terkait topik ini sudah banyak dilakukan, salah satunya adalah Alat Peraga Edukatif (APE) untuk Anak Usia Dini bagi Kepala Sekolah dan Guru Taman Kanak-Kanak berbasis kewirausahaan di Kecamatan V Koto Kampung dalam Kabupaten Padang Pariaman (Mahyuddin and Sofya 2019a), alat permainan edukatif sebagai media pembelajaran Bahasa Inggris (Apsari, Lisdawati, and Mulyani 2020), pengaruh pelaksanaan pelatihan terhadap pemahaman guru tentang Alat Peraga Edukatif (Mahyuddin and Sofya 2019b), pemanfaatan kain perca sebagai APE Pillow Doll untuk pembelajaran Anak Usia Dini (Rosdiana, Yulistianti, and Laila 2018), dan analisis kepuasaan pelaksanaan pendampingan pengembangan Alat Peraga Edukatif di Pekanbaru, Riau (Mujtahid et al. 2020).

Berbeda dengan penelitian dan pengabdian sebelumnya, sisi menarik dari kegiatan ini adalah sosialisasi terhadap siswa-siswi SDN Keboireng menggunakan APE dalam tanggap bencana yang ada di wilayah desa tersebut, sebab daerah ini rawan sekali adanya bencana seperti banjir, tanah longsor, dan juga gelombang air.

\section{METODOLOGI PENGABDIAN}

Langkah awal yang tim pengabdi lakukan adalah izin kepada Kepala Sekolah SDN Keboireng untuk bersosialisasi kebencanaan pada minggu keempat kepada seluruh siswa-siswi, dengan hasil disepakatilah izin untuk melakukan sosialisasi tanggap bencana ini. Selanjutnya adalah menjalankan tahap berikutnya yaitu; mengakses informasi dan inspirasi, mencari alat dan bahan, dan membuat serangkaian alat dan bahan menjadi satu kesatuan APE kebencanaan.

Kegiatan ini dilaksanakan dengan rancangan ceramah, simulasi, dan tanya jawab dengan peserta, yaitu siswa-siswi SDN Keboireng, Kecamatan Besuki, Kabupaten Tulungagung mulai dari kelas 1 sampai dengan kelas 6. Pelaksanaannya adalah pada tanggal 4, 5, dan 6 Februari tahun 2020. Kegiatan dilaksanakan pada saat jam sekolah dengan pertimbangan untuk mempermudah mengumpulkan dan mengorganisir siswa-siswi yang ada di SDN Keboireng tersebut.

Alat Peraga Edukatif ini dipilih sebagai media sosialisasi karena unik dan bertujuan mengenalkan kepada siswa-siswi yang sudah jarang mengenal media belajar tradisional, meski tradisonal media yang digunakan, ini tidak mengurangi kualitas dan isi dari materi yang diajarkan. Selain itu, di tengah gempuran arus globalisasi bagi generasi milenial yang sudah dimabukkan oleh alat elektronik semacam gadget, mengenalkan media tradisional menjadi sebuah trigger yang perlu dipertimbangkan.

Evaluasi yang dilakukan adalah dengan memberikan sebuah pertanyaan kepada siswa-siswi bagaimana seandainya ketika terjadi suatu bencana semisal; tanah longsor, banjir, ataupun gelombang pasang? Selain itu, evaluasi juga dilakukan dengan cara melihat aktivitas siswa-siswi di dalam menjaga lingkungan masing-masing dengan tidak membuang sampah di sembarangan tempat, menjaga kebersihan lingkungan rumah, dan lain sebagainya.

\section{HASIL DAN PEMBAHASAN}

Pelaksanaan kegiatan ini adalah pada tanggal 4,5,6 Februari 2020, pengabdian dan penelitian ini bekerjasama dengan mahasiswa KKN Tangguh Bencana Desa Keboireng, Kecamatan Besuki, Kabupaten Tulungagung. Kegiatan ini merupakan tindakan nyata dalam menumbuhkan generasigenerasi penerus bangsa millennial yang paham akan informasi dan teknologi yang berkembang pada setiap tahunnya dan untuk mengendalikan arus globalisasi 
yang terus berkembang pesat setiap dentang guliran waktu, yaitu kami mengambil langkah dengan membekali pengetahuan kebencanaan kepada seluruh siswa SDN Keboireng melalui APE (Alat Peraga Edukatif).

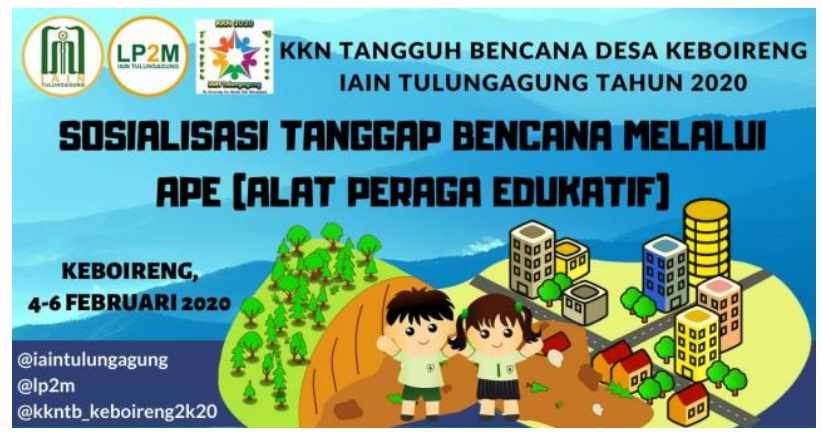

Gambar 1. Foto back ground kegiatan sosialisasi tanggap bencana melalui APE

Meskipun banyak dari peserta yang sudah mengenal gadget, tidak menutup kemungkinan peserta belum banyak mengakses pengetahuan kebencanaan yang sebenarnya sangat dibutuhkan oleh peserta / anak didik (Wardyaningrum 2014). Hal ini disebabkan banyak anak seumur peserta yang malah menjadikan alat teknologi untuk mengakses hal-hal yang tidak sepatutnya diakses pada seusia siswa-siswi SD. Maka dari itu, diperlukan adanya perlakuan pengajaran mengenai pengetahuan dan bimbingan secara langsung dari orang yang lebih paham terhadap sesuatu bidang yang berusia di atas siswa-siswi tersebut.

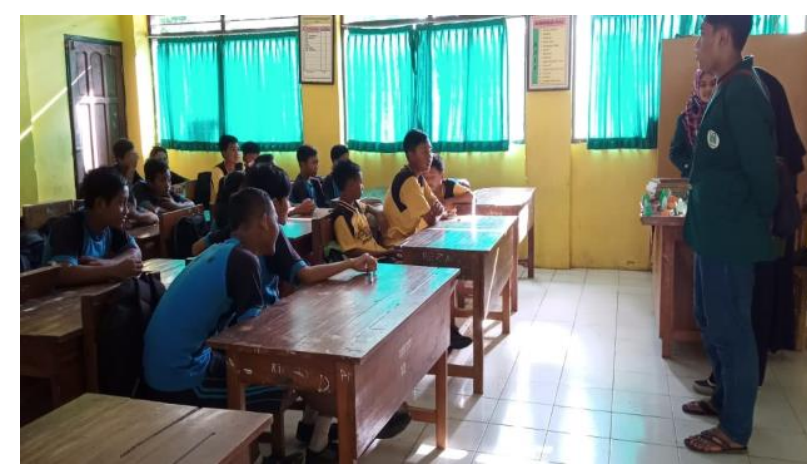

Gambar 2. Foto pengarahan sebelum kegiatan sosialisasi kepada siswa-siswi SDN Keboireng

Pembuatan APE ini berkisar kurang lebih selama 2 minggu sebelum pelaksanaan sosialisasi dengan bantuan semua mahasiswa KKN.

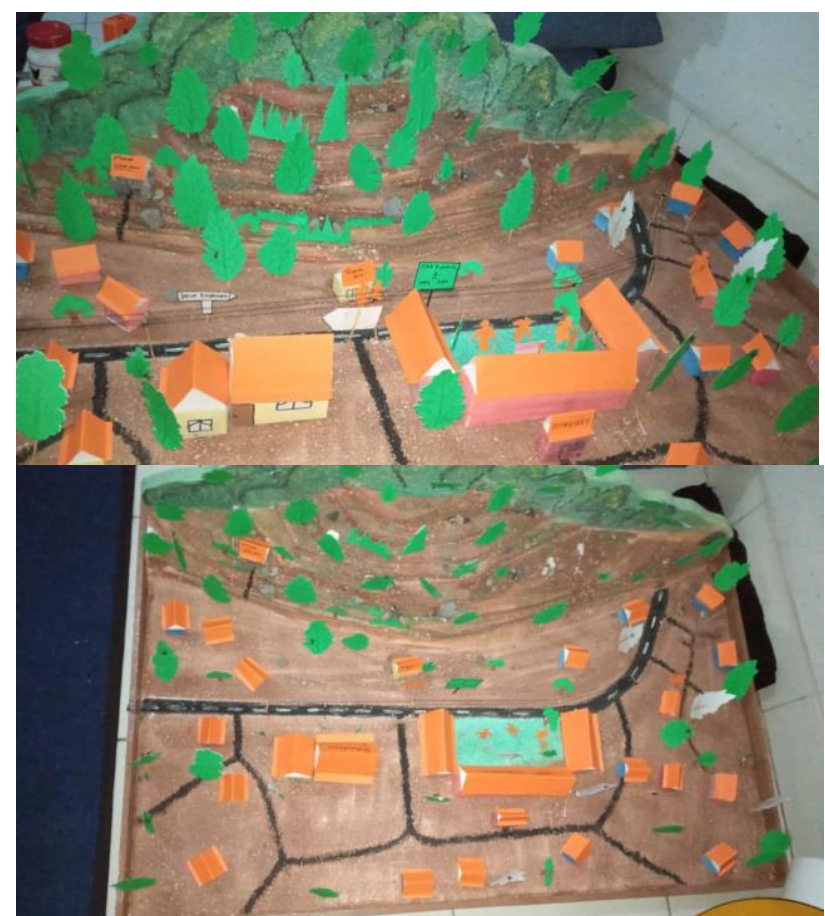

Gambar 3. Foto APE (Alat Peraga Edukatif)

Sosialisasi tanggap bencana melalui APE (Alat Peraga Edukatif) ini dilaksanakan selama 3 hari yaitu pada tanggal 4,5, dan 6 Februari 2020 ditujukan kepada kelas 1 dan 2 pada hari Selasa, kelas 5 dan 6 pada hari Rabu, dan kelas 3 dan 4 pada hari Kamis di SDN Keboireng dengan jumlah pemateri dari Mahasiswa KKN sebanyak 6 orang.

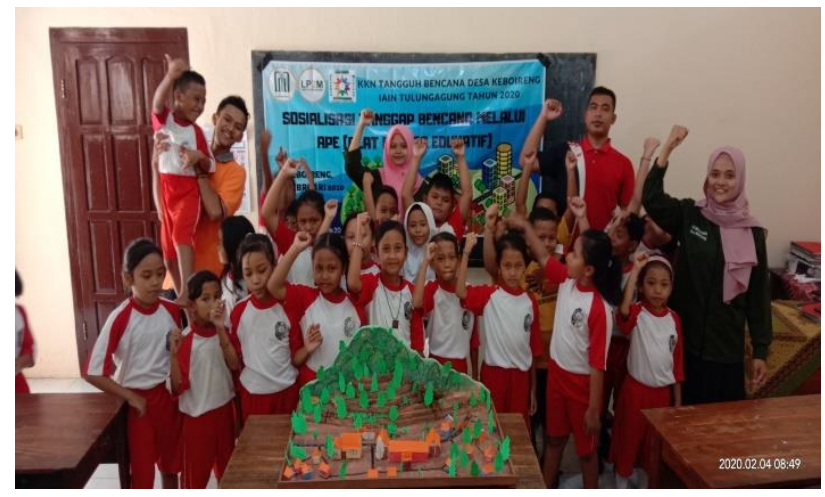

Gambar 4. Foto dengan siswa-siswi SDN Keboireng kelas 1 dan 2

Penyampaian sosialisasi dengan media APE yang merupakan miniature desa Keboireng sangat diapresisasi oleh siswa-siswa tersebut. Mereka sangat memperhatikan apa yang disampaikan oleh pemateri. Tidak hanya materi kebencanaan yang disampaikan, melainkan juga melalui lagu "kalau ada gempa" sehingga membuat peserta dengan mudah memahami 
tindakan yang harus dilakukan dengan tanggap ketika terjadi bencana gempa bumi.



Gambar 5. Foto dengan siswa-siswi SDN Keboireng kelas 5 dan 6

Sosialisasi dengan bantuan media APE dilakukan ini, merupakan suatu cara dari pengabdian dalam memahamkan terkait bencana-bencana yang mungkin terjadi di Desa Keboireng (Suwardi, Firmiana, and Rohayati 2016) (Riadin and Fitriani 2018). Mulai dari penanganan sebelum terjadi bencana, saat terjadi bencana maupun setelah bencana yang dijelaskan dengan memperagakan APE. Karena dalam APE yang dibuat, menggambarkan sebuah miniature mulai dari gunung Tanggul beserta pepohonannya, tanah yang gundul, Balaidesa, SDN Keboireng, perumahan penduduk, dan orang-orang yang berkumpul di titiktitik tertentu. Sehingga dalam menyampaikannya sangat mudah dimengerti oleh para siswa, karena telah mengenal tempat-tempat yang ada.

Penyampaian sosialisasi berlangsung kurang lebih 1 jam di setiap kelasnya. Dengan jumlah kelas setiap harinya 2, maka diatur dengan bergantian masuk dalam tiap kelas. Dengan skema yang satu masuk dan satu pemanasan olahraga. Di setiap akhir penyampaian ada pemberian materi kepada para siswa-siswi untuk menjaga lingkungan sekitar, sebab lingkungan sekitar merupakan bagian penting dari kestabilan ekosistem alam, selalu menjaga kebersihan dan hidup di alam dengan penuh kegembiraan.

Evaluasi yang dilakukan adalah dengan memberikan sebuah pertanyaan kepada siswa-siswi bagaimana seandainya ketika terjadi suatu bencana seperti tanah longsor, banjir, ataupun gelombang pasang? Selain itu, evaluasi juga dilakukan dengan cara melihat aktivitas siswa-siswi di dalam menjaga lingkungan masing-masing dengan tidak membuang sampah di sembarangan tempat, menjaga kebersihan lingkungan rumah, dan lain sebagainya.

Rencana Tindak Lanjut (RTL) yang dilakukan oleh pengabdi adalah dengan selalu memonitoring ke tempat pengabdian tersebut setiap sebulan sekali, selain itu juga memberikan pengetahuan yang baru berkaitan dengan cara penanggulangan bencana yang mungkin akan terjadi di sekitar tempat tersebut.

\section{Ucapan Terima Kasih}

Ucapan terima kasih pengabdi haturkan kepada Kepala Desa Keboireng, jajaran perangkat desa dan Warga Desa Keboireng yang sudah mengizinkan pengabdi melaksanakan pengabdian di tempat berlangsung.Selain itu ucapan terima kasih diberikan kepada Kepala Sekolah SDN Keboireng beserta guru SDN Keboireng dan para siswa-siswi SDN Keboireng.

\section{PENUTUP}

\section{Kesimpulan}

Kegiatan pengabdian sosialisasi tangguh bencana melalui APE (Alat Peraga Edukatif) ini memberikan manfaat bagi siswa-siswi. Hal ini bisa dilihat dari siswa-siswi SDN Keboireng yang antusias, tertarik, dan senang terhadap materi yang disampaikan oleh pemateri dengan metode simulasi, ceramah, dan tanya jawab. Sehingga siswa-siswi mampu mengaplikasikannya ketika saat nanti bencana datang, baik longsor, banjir, maupun gelombang pasang.

\section{Saran}

Pengabdian dengan topik sosialisasi tanggap bencana melalui APE (Alat Peraga Edukatif) di SDN Keboireng ini tentu bukan akhir dari upaya memberikan kesadaran warga Desa Keboireng terhadap bencana yang datangya tidak bisa diprediksi. Tentu perlu support dari pihak pemerintah yang berwenang untuk upaya lebih lanjut. Kolaborasi masyarakat dan pemerintah tentu akan menjadikan kesadaran terhadap tanggap bencana semakin baik.

Pengetahuan terhadap kesadaran tanggap bencana sebaiknya sudah ditanamkan sejak dini terhadap anak-anak, mulai dari pendidikan PAUD, TK, sampai SD. Hal ini akan menjadikan kesadaran tanggap 
bencana menjadi lebih baik bagi siswa-siswi. Penanaman pengetahuan sejak dini ini akan tetap menancap pada ingatan anak-anak.

\section{DAFTAR PUSTAKA}

Afrian, Ramdan. 2020. "Kajian Mitigasi Terhadap Penyebab Bencana Banjir Di Desa Sidodadi Kota Langsa." Jurnal Georafflesia: Artikel Ilmiah Pendidikan Geografi 5(2):165-69.

Anisah, Nisfi. 2019. "Model Sekolah Aman Bencana Dalam Upaya Mewujudkan Pendidikan Karakter Di MIN 1 Bantul.” LITERASI (Jurnal Ilmu Pendidikan) 10(1):9-20.

Anon. n.d. "Desa Keboireng - Kec. Besuki - Kab. Tulungagung." Retrieved February 19, 2021 (http://keboireng.tulungagungdaring.id/).

Apsari, Yanuarti, Ida Lisdawati, and Euis Rina Mulyani. 2020. "Alat Permainan Edukatif Sebagai Media Pembelajaran Bahasa Inggris." Abdimas Siliwangi 3(1):38-47.

Baso, Anang. n.d. "Rela Urunan Bangun Tanggul, Warga Keboireng Tetap Terancam Banjir Langganan | Jatim TIMES.” Retrieved February 19, 2021 (https://jatimtimes.com/baca/161154/2017110 3/130437/rela-urunan-bangun-tanggul-wargakeboireng-tetap-terancam-banjir-langganan).

Binsasi, Remigius, Retno Peni Sancayaningsih, and Sigit Heru Murti. 2017. "Analisis Ekologis Vegetasi Pohon Di Daerah Tangkapan Air (DTA) Mata Air Geger Kabupaten Bantul Yogyakarta." SAINTEKBU: Jurnal Sains Dan Teknologi 9(2):57-66.

Hayudityas, Beatrix. 2020. "Pentingnya Penerapan Pendidikan Mitigasi Bencana Di Sekolah Untuk Mengetahui Kesiapsiagaan Peserta Didik." Jurnal Edukasi NonFormal 1(2):94102.

Khairul Rahmat, Hayatul, and Anwar Kurniadi. 2020. "Integrasi Dan Interkoneksi Antara Pendidikan Kebencanaan Dan Nilai-Nilai Qur'ani Dalam Upaya Pengurangan Risiko Bencana Di Sekolah Menengah Pertama." Pp. 455-61 in Prosiding Konferensi Integrasi Interkoneksi Islam dan Sains. Vol. 2.

Kurniawan, Dede Trie, Sri Maryanti, Astri
Yuliawati, and Nailah Tresnawati. 2019. "Program Edukasi Lingkungan Hidup Bagi Siswa RA Untuk Memahamkan Konsep 'Kang Pisman' Melalui Kegiatan Bermain." $\mathrm{Al}$ Khidmat 2(1):1-6.

Mahyuddin, Nenny, and Rani Sofya. 2019a. "Pelatihan Pembuatan Media Alat Peraga Edukatif (APE) Untuk Anak Usia Dini Bagi Kepala Sekolah Dan Guru Taman KanakKanak Berbasis Kewirausahaan Di Kecamatan V Koto Kampung Dalam Kabupaten Padang Pariaman." Jurnal Ecogen 2(4):601-8.

Mahyuddin, Nenny, and Rani Sofya. 2019b. "Pengaruh Pelaksanaan Pelatihan Terhadap Pemahaman Guru Tentang Alat Peraga Edukatif." Jurnal Manajemen Dan Kewirausahaan 10(4):1-13.

Mujtahid, Iqbal Miftakhul, Mery Berlian, Rian Vebrianto, and Musa Thahir. 2020. "Analisis Kepuasaan Pelaksanaan Pendampingan Pengembangan Alat Peraga Edukatif Di Pekanbaru, Riau." Tasnim Journal for Community Service 1(1):27-34.

Oktaviani, Nuni. 2020. "Kajian Tentang Dampak Bencana Banjir Terhadap Perekonomian Di Sekitaran Masyarakat Pinggiran Sungai Cimanuk." Jurnal Tasyri': Jurnal Muamalah Dan Ekonomi Syariah 2(1):1-16.

Oktradiksa, Ahwy, and Minzani Aufa. 2019. "PKU Bagi MI Muhamamdiyah Rambeanak 2 Kabupaten Magelang, Melalui Alat Peraga Edukatif (APE)." Publikasi Pendidikan 9(3):227-31.

Pahleviannur, Muhammad Rizal. 2019. "Edukasi Sadar Bencana Melalui Sosialisasi Kebencanaan Sebagai Upaya Peningkatan Pengetahuan Siswa Terhadap Mitigasi Bencana." Jurnal Pendidikan Ilmu Sosial 29(1):49-55.

Riadin, Agung, and Cici Liani Fitriani. 2018. "Upaya Meningkatkan Hasil Belajar Ipa Menggunakan Model Pembelajaran Kooperatif Tipe Jigsaw Dengan Berbantuan Media Alat Peraga Konkret Pada Peserta Didik Kelas V SDN-4 Kasongan Baru Tahun Pelajaran 2016/2017." Pedagogik: Jurnal Pendidikan 13(2):1-5.

Rosdiana, Aliva, Hayu Dian Yulistianti, and Azzah 
Nor Laila. 2018. "Pemanfaatan Kain Perca Sebagai APE Pillow Doll Untuk Pembelajaran Anak Usia Dini." Journal of Dedicators Community 2(1):1-7.

Suwardi, Suwardi, Masni Erika Firmiana, and Rohayati Rohayati. 2016. "Pengaruh Penggunaan Alat Peraga Terhadap Hasil Pembelajaran Matematika Pada Anak Usia Dini." Jurnal Al-Azhar Indonesia Seri Humaniora 2(4):297.

Wardyaningrum, Damayanti. 2014. "Perubahan Komunikasi Masyarakat Dalam Inovasi Mitigasi Bencana Di Wilayah Rawan Bencana Gunung Merapi.” Jurnal ASPIKOM 2(3):179. 